\title{
Organization of work of general educational organizations with families on the spiritual and moral development of students
}

\author{
Irada Mekhdieva ${ }^{1, *}$ Liliya Ibragimova ${ }^{1}$ \\ ${ }^{1}$ EDP Sciences, Nizhnevartovsk State University Nizhnevartovsk, Russia
}

\begin{abstract}
The article is devoted to the urgent problem of cooperation of the educational organization with the families of students. The article provides a meaningful analysis of the opportunities and prospects of educational and other organizations that carry out educational activities of children in the implementation of the Education Development Strategy in the Russian Federation for the period up to 2025, the Education Development Strategy of the Khanty-Mansiysk Autonomous Okrug - Ugra until 2020, and the Concept of State Family Policy in Russian Federation for the period until 2025 and other federal documents. Educational programs aimed at solving the problems of education, development, and socialization of students are the objects of analysis of this study.
\end{abstract}

\section{Introduction}

Nowadays, the problems of organizing work of general educational organizations with families have acquired a special significance in connection with the "fuzziness" of the spiritual, moral, and ethical guidelines of modern society. The substantial uncertainty of norms, the weakening of social regulation distort cultural and spiritual foundations. These negative trends in society have particularly affected the relationship between children and their parents, as well as between children and their caregivers.

The modern family is experiencing global economic and spiritual-moral difficulties, which contributes to the growth of alienation between parents and children to such an extent that it has become a genuine national problem. Not all modern parents have a sufficient level of general culture and pedagogical knowledge necessary for the upbringing and socialization of the child. Some parents are passive; they do not want to change anything, and change themselves, do not understand the goals of working together with the school and their role in it. Other parents are ready to cooperate with the school in raising their children, but they grew up in an era of global change in the 90s of the twentieth century, so they may not have clear guidelines that form the basis of fundamental national values. Today, the pedagogical interaction of the school and the family allows the influence of the quality of family education and to a large extent, neutralizes its shortcomings.

In matters of psychological and pedagogical support of families, one of the fundamental problems is the problem of the formation of spiritual and moral values within the family. The set of value attitudes inherent in modern mass consciousness, including children's consciousness, is mainly destructive and destructive from the development of the individual, family, and state. However, today, there are educational programs that have many years of testing technologies for the formation of fundamental national values in children of all levels of general education and their parents and guardians. Thus, the implementation of the "'Sociocultural Origins"" program promotes the formation in children of a holistic view of the sociocultural environment in which they live and develop, leads them to understand the existence of the human inner world and the relationship between the past, present, and future, and stimulates motivation for selfimprovement of the 'child's personality. In other words, it allows creating conditions so that the child from the information carrier turns into a carrier of experience.

One of the central pedagogical problems in multicultural regions is the search for new technologies, methods, and forms aimed at supporting the family in matters of spiritual and moral education and development of children. In this regard, the problem of organizing work with families in educational organizations is of particular importance. An analysis of the state of the issue under study in psychological and pedagogical theory and practice showed that problems could not be resolved within the framework of the traditional educational paradigm. To overcome difficulties in organizing work with families of students, one of the relevant areas, in our opinion, is targeted psychological and pedagogical support of the family at all levels of general education.

\section{Materials and methods}

The problem of organizing work with families has received multilateral coverage in the scientific literature. Many philosophers develop questions of the influence of

*Corresponding author: irada_mekhdieva@mail.ru 
social transformations on the personality and also analyze the ratio of objective conditions and subjective factors of personality development (E.V. Ilyenkov, M.S. Kagan, P.P. Lyamtsev, A.V. Myalkin, B.D. Parygin, G.L. Smirnov, G.N. Filonov, I.T. Frolov and other philosophers).

Psychologists reveal the internal mechanisms of organizing work with families of students in educational organizations (A. Adler, A. Bandura, E. Simpson, C. Steiner, Z. Freud, C. Jung, and other psychologists)

Researchers turn to various aspects of the psychological and pedagogical support of the family (O.S. Gazman, A. Danilova, E.I. Kazakova, N.L. Konovalenko, E. Parslow, N. Samoukina, N. Turkulets, J. Whitler, N.A. Farreitor and other scientists).

Also, the theoretical basis of the study is works of A.N. Yakunina (Pedagogical conditions for the formation of family education in Russia: a culturalhistorical approach, dissertation for the degree of candidate of pedagogical sciences. Moscow, 2014); Kovalenko T.V. (Modeling the interaction of family and school in modern primary education. Omsk, 2016); Karpushina N.Ya. (Pedagogical design of the development of the regional system of secondary education in the context of its modernization. Nizhny Novgorod, 2012); Moleva T.N. (Formation of spiritual and moral values of children and parents in a school family club, Veliky Novgorod, 2014) and others.

The study of the modern system of organization of work with families involves the study and analysis of regulatory documents, guidelines, development programs of educational organizations. This analysis showed that the documents do not adequately describe the work with families in implementing educational and development programs for students. Moreover, the problems caused by these features are becoming more and more acute.

Therefore, we can say that working with families of students in the implementation of education and development programs does not add up to a system that encompasses social, pedagogical, and psychological support. This problem is especially acute in elementary school since a younger student is a person focused on educational activities as a leader and not a parent, but a teacher becomes a significant adult in this period.

At the turn of the XX-XXI centuries, the educational program "Sociocultural Origins" took the significant step towards implementing a unique educational program in various regions of the Russian Federation aimed at creating a systematic sociocultural approach to educating and educating young people. The integrated experience tested over 15 years allows us to speak about the unchanging spiritual and moral potential of the Sociocultural Origins program, which contributes to the preservation and enhancement of universal and religious values based on the achievements of national culture.

Today, one of the main directions of Russian pedagogy is that it addresses spiritual and moral values, which is one of the priority areas for the development of modern education [3] and upbringing. This direction is currently the most promising since it is connected with the upbringing of traditions and lifestyles.

At present, there is an ever clearer understanding that the revival of Russia is impossible without resorting to the rich spiritual and moral heritage of our Fatherland. "Although we are part of world civilization, the preservation and development of our cultural and national identity is becoming a priority for us now," emphasizes the Chairman of the Government of the Russian Federation V.V. Putin

The course "Sociocultural Origins" gives children a systematic view of the central values in life. In elementary school, a child forms and develops a system of vital sociocultural and spiritual-moral values. From the first years of familiarization with the sources, he is capable of determining what is most important to him in life.

Grade 1: children come to understand the essence of the Origins based on the categories of world, word, image, book. The five talents of the Golden Heart reveal the value meaning of the word - Good word, Honest word, a word about Parents, Labor and Feat, Holy Word. From grade 1, the child's ability to distinguish between the image and the ugly, to hear the word of folk wisdom, to love a book, develops.

Grade 2: children get acquainted with the origins of the sociocultural and spiritual-moral environment closest to the child and the main human activity in it.

Grade 3: children learn the origins of the values of the human inner world.

Grade 4: children get acquainted with the origins of traditions in their culture as the most important mechanism for preserving and transmitting the fundamental values of Russian civilization.

All four classes of an elementary school in interaction with system-forming categories are connected by the primary value of the Origins - life. The living space of a child, family, school is developing. Thus, the educational process is revived.

Our efforts develop the world of spiritual and moral values. Only when moral knowledge becomes felt experience, does the increment of the spiritual and moral basis of personality.

The implementation of Origins' pedagogical technology makes it possible to effectively organize the activities of students to master the concepts of the course.

The basis of the educational process of the sociocultural systems approach to the origins in education is the active form of learning. In source studies, the systemic development of active forms is of particular importance.

Participating in ongoing classes, the people form an integral system of values, consolidate the mastered knowledge, and include them in their life experience. The entire group of students participates in such practical exercises, which allows children to receive an objective assessment of their development through feedback in the communication process. Active forms of learning are an essential component of each lesson, its core, an open dialogue aimed at the joint reflection. 
In a systematic approach, special attention is paid to the origins of education, which requires the development of sociocultural tools. Sociocultural tools include teaching aids, methods for conducting active classes, texts containing spiritual, moral and sociocultural categories, an audiovisual series, and didactic materials.

Sociocultural tools serve for the development of mental functions (perception, thinking, feeling), helps to comprehend the material, and, which is very important for the development of the child, sets the child up for a soulful conversation with her parents and teachers. Visual aids can be created in a lesson during a conversation jointly by the teacher and students. It is essential for the teacher to creatively use the sociocultural tools in the continuation of the lesson, skillfully structure it according to the stages of the lesson. A holistic system of active learning forms is constructed in such a way that each subsequent level consolidates and develops the level already achieved by students during the previous stage of work by conducting systems and acting classes in general, and not selectively. A holistic system of active forms of learning can lead to a significant sociocultural result of learning, as it allows developing the spiritual and moral foundation of a student, group, and teacher. The student and teacher are in a joint process of spiritual creation. In each lesson using the active form, the teacher is spiritually updated.

The program "Social Sources" offers a systematic version of development not only for the student, but also for the teacher, and also helps to recreate the original context of education based on spiritual and moral values and categories." A teacher who teaches the themes of faith, spirituality, and patriotism himself must become a living example; remember the most significant moral responsibility that lies with him.

Work with parents is an essential key element in the implementation of the Sociocultural Origins program for educational institutions. Recognizing the fact that his family plays a crucial role in the spiritual and moral development of the child, the authors of the program came to an understanding 15 years ago that it was not enough to form a system of values for students. It is necessary to form a single system of values, both in the family and in general educational organizations. To this end, at the development stage, the program "Psychological and pedagogical support of students' families," in which it is planned to conduct joint events with students and their parents. These measures will ensure the natural harmonious spiritual and moral development of the individuals included in it, and unite the worldwide educational organization, families, and students into one compound structure.

The program "Sociocultural Origins", firstly, creates the conditions for the formation and implementation of a set of measures that take into account the characteristics of modern children, the social and psychological context of their development, and secondly, forms the prerequisites for consolidating the efforts of the family, society and the state aimed at educating the younger and future generations. Also, this program is responsible for the Federal Law "On education in the Russian Federation" [7], "Strategy for the Development of Education in the Russian Federation for the period until 2025" [8], "Strategies for the development of education in the Khanty-Mansiysk Autonomous Okrug - Ugra until 2020" [9].

The development strategies of education in the Russian Federation for the period up to 2025 is based on a system of spiritual and moral values that have developed in the process of cultural development of Russia: philanthropy; justice; honor; conscience; will; personal dignity; faith in good; desire to fulfill a moral duty to himself, his family and his Fatherland [6]. The above values are currently defined as "basic spiritual and moral values."

\section{Results}

The first area of research involves identifying a child's awareness of the relationship of close people to him through the use of N. Kaplan's projective methodology, which allows one to identify the perception of family relationships using the projective drawing "My Family."

Organizing the diagnostic process, we proceeded from the principle of reasonable sufficiency. Each new study was undertaken based on an analysis of previous diagnostic information.

During the diagnosis, the following results were obtained:

1. Most of the children in the sample are dominated by a reliable type of emotional attachment, which is $59 \%$ of the total number of respondents. It should be noted that the sample is quite prosperous in terms of social status and the presence of both parents, which increases the level of the emotional well-being of children. Studies of emotional attachment conducted by domestic scientists showed that depending on the contingent, the percentage of children with a reliable type of attachment varies from 48 to $66 \%$. In $27 \%$ of children, an anxiousavoiding type of emotional attachment was diagnosed. A feature of this type of attachment is the emotional distance from the object of attachment. Anxietyambivalent type was detected in $14 \%$ of children. A feature of this group is the manifestation of negative feelings about the emotional connection.

The second direction of the study is to identify the attitude of younger students to the family using a projective drawing of the family. The experiment involved the same children as in the previous direction of the study. The results of the experiment are presented in percentage terms in the table (Table 1). 
Table 1. Formal and substantive indicators of the figure "My family."

\begin{tabular}{|c|c|c|c|c|c|c|c|c|c|c|c|c|}
\hline \multicolumn{7}{|c|}{ The predominance of color, in $\%$} & \multicolumn{3}{|c|}{$\begin{array}{l}\text { Correspondence to the } \\
\text { number of family } \\
\text { members, in } \%\end{array}$} & \multicolumn{3}{|c|}{$\begin{array}{c}\text { Emotional background, } \\
\text { in } \%\end{array}$} \\
\hline gray & green & orange & yellow & red & brown & black & $>$ & $=$ & $<$ & + & - & - \\
\hline 20 & 14 & 2 & 15 & 15 & 17 & 17 & 0 & 41 & 59 & 9 & 68 & 23 \\
\hline
\end{tabular}

Analysis of the predominance of color in the image of a family drawing shows a lack of color preferences. It can be noted that children used almost equal proportions of dark and light colors, warm and cold colors, which indicates a diverse, often contradictory perception by children of the family situation. This observation is substantively confirmed by a high percentage of figures where one or the majority of the family members is missing; that is, the family is not entirely represented $(59 \%)$. An adequate number of family members in the drawings depicted $41 \%$ of primary school students. More than in reality, no child depicted family members. Moreover, a negative emotional background can be diagnosed in $23 \%$ of the figures, in $68 \%$ it is neutral, and in $9 \%$ it is positive.

The identification of the content of communication between parents and a child was determined using the questionnaire proposed in the methodology "Diagnostics of the content of communication between children and close adults" T. Yu. Andryushchenko and G.M. Shashlova results of the conduct, which are presented in the form of a diagram (Fig. 1).

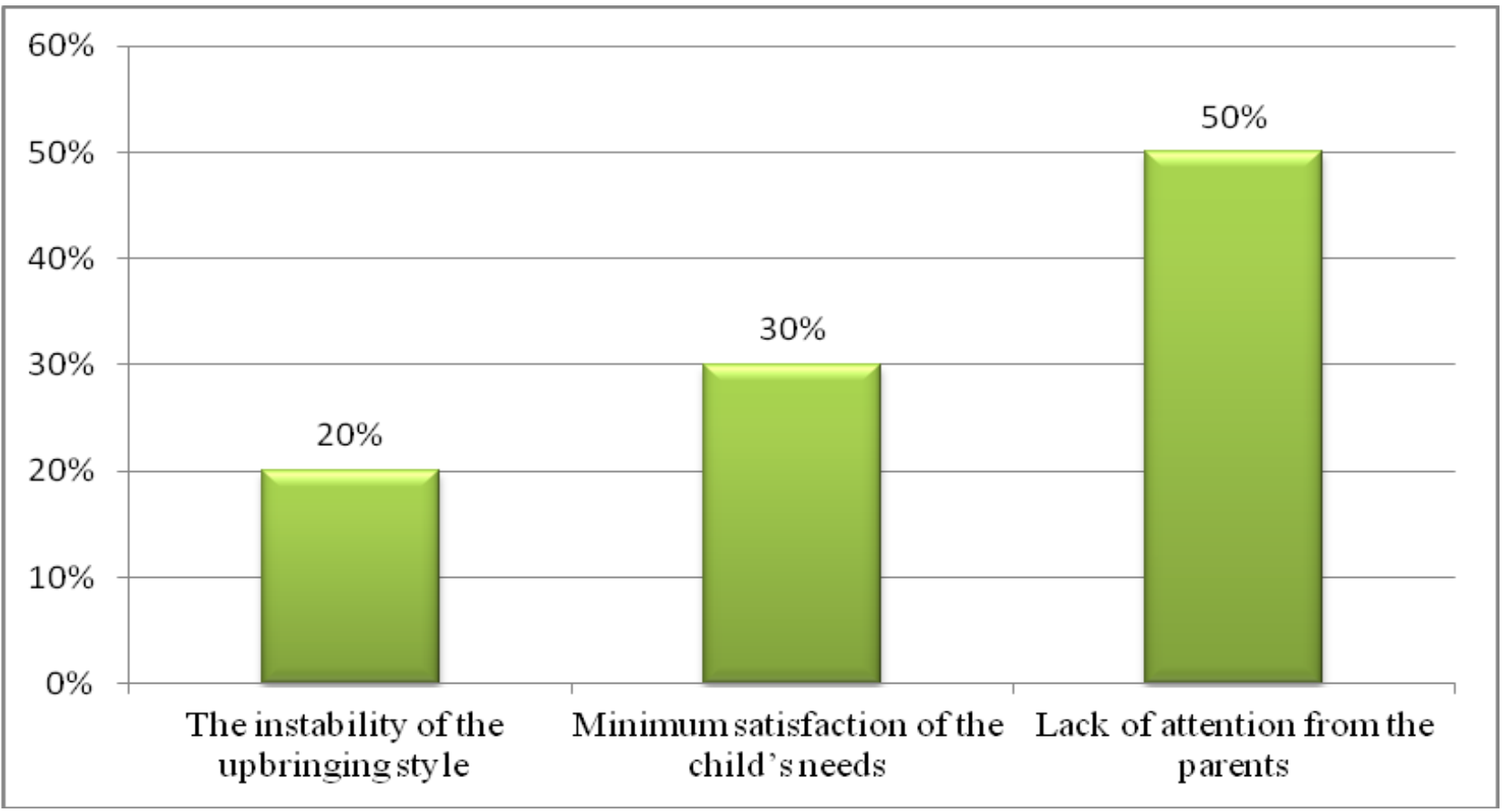

Figure 1. Diagnosis of the content of communication between children and close adults

Interpretation of the results revealed that $50 \%$ of the communication with the child is dominated by hepatoprotection (lack of attention from parents). $30 \%$ of respondents report a minimum satisfaction of the needs of the child, most cases in the form of neglect. The instability of the upbringing style was detected in $20 \%$. A feature of this group is the combination of various styles in education and the preference of children's qualities in a teenager. 
The study also applies the methodology "Communicative personality questionnaire for parents." This technique helps to identify the level of development of the communicative and personal characteristics of students. The uniqueness of this technique lies in the fact that it takes into account the analysis of the answers not only of the students themselves but also of their parents, we can conclude at what level the child has communication skills.

In the experimental work was attended not only by children but also by parents.

It was necessary to find out what parents understand by the term "spiritual and moral education," whether they are ready to contribute to the spiritual and moral formation of the child, the formation of his moral feelings, moral character, and moral behavior. In order to identify these indicators, we developed a questionnaire where students of students were asked to answer several questions. The survey was attended by 45 representatives of the parental community, among whom $75 \%$ were between the ages of 30 and 50, 25\% were between the ages of 20 and 30 . Of these, $75 \%$ worked in other fields, $14 \%$ in an educational organization, and $11 \%$ do not work for various reasons.

After analyzing the answers of parents, we can draw the following conclusions. It becomes apparent that it is in the family that a person receives the first spiritual and moral education and begins to develop a moral life in himself. Family is the school of holy, patient, and selfless love. According to the results of the study, it was found that greater openness for the parental community from educational and other organizations is needed. Among the few wishes were, as a rule, proposals for joint events. Thus, the obtained experimental data allow us to talk about the need to develop a program of psychological and pedagogical support "Spiritual and moral development of families in the context of the Sociocultural Origins ' program."

\section{Discussion}

The method of statistical data processing was used Student's t-test for establishing the reliability of results.

Based on the results, it can be argued that the indicators are changing in the direction of improvement. Positive dynamics are established in the development of the creative imagination of senior preschool children with speech impairment by non-traditional drawing techniques.

Under the program of psychological and pedagogical support, we understand the complex of interconnected psychological and pedagogical measures aimed at achieving the development goals of students. The implementation of activities will be limited to a specific time frame. In appearance, the proposed program of psychological and pedagogical support will be developmental and educational. This statement is based on the understanding, first, of developing psychological and pedagogical programs as programs aimed at the most complete disclosure of the intellectual and personal potential of students, the formation and development of their socio-psychological skills, development of creativity, and secondly, educational (educational ) psychological and pedagogical programs as programs aimed at the formation of psychological knowledge, increasing the level of psychological culture and psychological competence of students.

In the course of the program, it is expected, firstly, to organize the educational activities of teachers and psychologists aimed at working with families of students under the program "Sociocultural Origins"; secondly, the creation of conditions for the formation and development of families of students of a general educational organization of spiritual and moral values; thirdly, increasing the level of parents' competence in preserving and strengthening family traditional values.

In this study, we proceeded from the fact that the family is a living open holistic system, and its maintenance is an urgent management task in an educational organization. In this regard, the following research tasks were posed and solved.

A literature analysis was carried out on the problems of spiritual and moral development of families, psychological and pedagogical support of families. In the framework of this study, psychological and pedagogical support was understood as "the professional activity of adults interacting with the child in the school environment" (V.I. Schegol). It was found that one of the most productive approaches when working with families is a systematic approach. The state of knowledge of the problem of working with families of students in the program "Sociocultural Origins" in psychological and pedagogical literature is determined.

The specificity of the organization of psychological and pedagogical support for families of students in educational organizations has been clarified. In this regard, it was found that modern schools implementing the "Sociocultural Origins" program are focused on the formation of fundamental spiritual and moral values in both children and their parents, based on the fact that the fundamental spiritual values that have developed in cultural Russia's development include: humanity; justice; honor; conscience; will; personal dignity; faith in good; the desire to fulfill a moral duty to himself, his family and his Fatherland.

Based on experimental data (interviewing and diagnosing students and their parents, teachers), a program of psychological and pedagogical support for families was developed and tested, which includes the organization and conduct of events and classes with families of students, which are aimed at increasing the level of formation of fundamental spiritual values.

\section{Conclusion}

Testing showed that the measures implemented during the formative phase of the experiment are useful, as evidenced by the dynamics of the formation of fundamental spiritual values. The study involved 25 students aged $9-10$ years and 45 parents (average age 
35 years) with different levels of education and professional orientation. The study revealed that among the few wishes were, as a rule, proposals for joint activities. Program participants recognize the fact that problems in relations with relatives, lack of attention from parents "impoverish" the spiritual and moral component of family development.

Thus, it should be noted that this study is one of the options for solving the problem, further application of which is possible for the development of methodological materials that provide practical psychological and pedagogical support for families in which children study under the "Sociocultural Origins" program.

\section{References:}

1. S.Yu. Divnogortseva, Spiritual and moral education in the theory and experience of Orthodox pedagogical culture. Moscow: PSTGU Publishing House, 237 (2012).

2. A. Dragomiretsky, Bulletin of the Baltic Pedagogical Academy. The new spiritually oriented concept of human personality, 77, 93-96 (2007).

3. L. Ibragimova, I. Skobeleva, Media Education. Conditions for creation and development of media culture in students of secondary professional education, 1, 89-94 (2018).

4. A.N. Leontiev, Activities. Consciousness. Personality. Moscow: Politizdat (1975).

5. B.T. Likhachev Philosophy of education. Moscow: Enlightenment: Vlados (1995).

6. N.D. Nikandrov, Russia: Socialization and education at the turn of the millennium. Moscow: Helios ARV (2000).

7. On education in the Russian Federation (Federal Law N 273-FL dated December 29, 2012 (as amended on July 3, 2016). Retrieved from: http://www.consultant.ru/cons/cgi/online.cgi?req=do c; base $=$ LAW;n=201339\# (2016).

8. Strategies for the development of education in the Russian Federation for the period until 2025 (Order of the Government of the Russian Federation of 05.29.2015 No. 996-r) Retrieved from: http://www.consultant.ru/law/hotdocs/43281.html (2016).

9. Strategies for the development of education in the Khanty-Mansiysk Autonomous Okrug - Ugra until 2020 (Order of the Government of the Khanty-Mansi Autonomous Okrug-Ugra from 02.19.2010 91-rp) Retrieved from: http://nosh11.ru/docstation/com (2016). 